\title{
A inflação brasileira na década de 2000 e a importância das políticas não monetárias de controle
}

\author{
Julia de Medeiros Braga**
}

\begin{abstract}
Resumo
Neste trabalho são apresentadas estimativas para a inflação brasileira na década de 2000. Os resultados de um modelo "estrutural" com duas variáveis endógenas - a inflação do produto e a inflação salarial - apontam que: $i$ ) o indicador de demanda não apresentou significância estatística na equação da inflação de bens e serviços, mas sim na equação da variação salarial; ii) houve predominância da influência de pressões cambiais e da evolução dos preços das commodities na explicação da inflação cheia. Porém, estimativas desagregadas em bens de consumo e serviços indicaram a predominância dos salários como variável explicativa dos preços dos serviços não monitorados. As pressões salariais da segunda metade da década, contudo, puderam ser acomodadas parcialmente devido ao crescimento da produtividade no período. Por fim, as evidências reportadas para os preços monitorados sugerem ainda que políticas não monetárias adotadas nesta década, de natureza regulatória e tributária, foram eficazes no controle da inflação.
\end{abstract}

Palavras-chave: Inflação; Economia brasileira; Políticas não monetárias de controle da inflação; Conflito distributivo; Séries temporais.

\section{Abstract \\ Brazilian inflation in the 2000s and the importance of non-monetary control policies}

This paper presents estimates of Brazilian inflation during the 2000. The results of a structural model with two endogenous variables - wage inflation and product inflation - indicate that: $i$ ) the demand indicator was not statistically significant in the product inflation, but was important in explaining wage inflation; ii) variations in the exchange rate and commodity prices were the key determinants to product inflation. Disaggregated estimates revealed that wages played a significant role in determining the price variations of consumer goods and services (not administered by the government). However, wage impacts on final prices in the aggregate model were not significant due to the rise in productivity. Finally, the evidence reported on administered prices by the government suggested that non-monetary policies that were adopted in this decade, consisting of regulatory and fiscal measures, were effective in controlling inflation.

Keywords: Inflation; Brazilian economy; Price controls; Conflict claims; Time series. JEL E31, E6.

* Trabalho recebido em 14 de julho de 2011 e aprovado em 12 de junho de 2012.

** Professora adjunta da Faculdade de Economia da UFF (Universidade Federal Fluminense) / Bolsista PNPD (Programa de Pesquisa para o Desenvolvimento Nacional) do Ipea (Instituto de Pesquisa Econômica Aplicada), Niterói, RJ, Brasil. O trabalho contou também com o Auxílio de Pesquisa APQ1 da Faperj (Fundação de Amparo à Pesquisa do Estado do Rio de Janeiro). A autora agradece a Ricardo Carneiro, Carlos Pinkusfeld Bastos, Roberto Messenberg, Claudio Amitrano e Thiago Martinez pelos comentários e sugestões, eximindo-os de qualquer responsabilidade sobre as opiniões emitidas nesse trabalho. E-mail: jbraga@id.uff.br. 


\section{Introdução}

Neste trabalho, procuramos investigar o processo inflacionário recente da economia brasileira na última década (de 2000 a 2010). O marco teórico adotado, muitas vezes denominado cost push inflation, segue os autores de tradição póskeynesiana, estruturalista (kaleckiana e latino-americana cepalina) e sraffiana. Estas linhas teóricas possibilitam o entendimento do processo inflacionário de maneira mais ampla que os modelos de Curva de Phillips tradicionais, tendo grande vinculação com os fatores estruturais e institucionais presentes em cada país. Assim, a questão da inflação é colocada para além de uma perspectiva de curto prazo da macroeconomia, envolvendo também fatores de médio e longo prazo relacionados ao próprio desenvolvimento econômico e a forma de distribuição da renda.

A análise é realizada para a inflação cheia e também para desagregações entre preços (ao consumidor) monitorados pelo governo e livres, estes últimos subdivididos em bens de consumo e serviços. Foram utilizadas como instrumento de análise ferramentas econométricas de séries temporais.

Procurar-se-á identificar quais dos principais tipos de inflação sugeridos na literatura pós-keynesiana e estruturalista melhor caracterizam a dinâmica da inflação na década de 2000. A tipologia utilizada denomina os principais tipos de inflação como inflação salarial, inflação de grau de monopólio (ou inflação de lucros), inflação importada, inflação spot (ou de commodities), inflação de impostos, inflação de retornos decrescentes e, por fim, a própria inflação de demanda (ver Sicsú, 2003).

Após esta introdução, a seção 1 contém a descrição da metodologia e a justificativa dos instrumentos econométricos adotados. A seção 2 é destinada à descrição dos resultados do processo de modelagem. Na seção 3, com base nos resultados obtidos, é feita uma análise do processo inflacionário da economia brasileira na década de 2000 , organizada segundo a tipologia dos principais tipos de inflação da literatura pós-keynesiana. A seção 4 expõe os limites da configuração atual, em termos das consequências negativas das políticas antiinflacionárias adotadas na década de 2000. Na seção 5 é descrita uma série de sugestões que servem como arcabouço no delineamento de políticas públicas antiinflacionárias auxiliares à política monetária e coerentes com os resultados encontrados. Na última seção estão as conclusões. A descrição do banco de dados utilizado foi colocada em um anexo, ao final do texto. 


\section{Referencial teórico e metodologia}

O marco teórico adotado segue os autores de tradição pós-keynesiana, estruturalista e de outras linhas de pesquisa heterodoxa, que identificam o processo inflacionário como sendo gerado, na maioria dos casos, por problemas do lado da oferta da economia, e não da demanda. Essa tradição, muitas vezes denominada cost push inflation, procura entender a formação de preços dos bens e serviços por meio do comportamento dos preços básicos (salários nominais, câmbio, lucro e insumos básicos) de uma economia descentralizada por processos distintos daqueles que refletem a escassez dos fatores de produção. Segundo Lavoie (1992), o fundamento econômico da visão pós-keynesiana para os determinantes da inflação é a existência de um conflito distributivo, uma disputa entre o trabalho e o capital sobre a renda real nacional ${ }^{1}$. Os modelos de conflito distributivo são variações da seguinte equação básica:

$$
\Pi=\Delta \mu+\Delta W-\Delta \gamma
$$

em que a inflação de produto (П) é explicada pelas interações entre variação percentual das margens de lucro $(\Delta \mu)$ e dos salários $(\Delta W)$ descontada a variação da produtividade. Tal equação é uma tautologia, e a teoria está nos determinantes de cada componente e suas interações. Para derivar uma equação de curto prazo para a inflação, supõe-se que a produtividade é constante (a tecnologia é dada) ${ }^{2}$. Os salários desejados dependem dos preços esperados enquanto os preços dependem dos salários nominais esperados. Ambas as taxas de inflação salarial e de produto são determinadas pela disparidade entre essas expectativas e a capacidade de cada parte de fazer valer suas preferências, aumentando sua participação na renda nacional.

$$
\begin{aligned}
& \Delta W=\Omega_{1}\left(w^{d}-w\right)+\Omega_{2} \Pi^{\mathrm{e}} \\
& \Pi=\Psi_{1}\left(w-w^{f}\right)+\Psi_{2} \Delta W^{e}
\end{aligned}
$$

(1) Vários autores adotaram este tipo de modelagem de conflito distributivo, muitos influenciados pelo artigo seminal de Rowthorn (1977). Para uma referência marxista, ver Saad Filho (1999). Para uma referência sraffiana, ver Stirati (2001, p. 430-439) e, para uma aplicação ao caso brasileiro seguindo esta abordagem, ver Bastos e Braga (2010). Para exemplo da visão estruturalista, ver Vásquez (1957). Embora não formalizem um modelo matemático, autores da tradição cepalina utilizam o conceito e a concepção do conflito distributivo como causa de um processo inflacionário.

(2) O conflito distributivo resulta em uma relação inversa entre os salários e lucros, que ocorre sempre que se adota a hipótese de que a "tecnologia" da economia está dada. Por tecnologia se entende toda a estrutura produtiva da economia, incluindo o padrão tecnológico das máquinas, equipamentos e processos produtivos, as condições de infraestrutura e o grau de adensamento da cadeia produtiva. O crescimento da produtividade permite que os trabalhadores obtenham ganhos salariais sem pressionar negativamente a taxa de lucro dos empresários. Essa questão será discutida na seção 4 . 
$w$ é a participação dos salários na renda, $w^{d}$ é a participação almejada pelos trabalhadores e $w^{f}$ é a participação desejada pelas firmas (de acordo com seu markup desejado, já que para dada tecnologia ambos são inversamente relacionados). $\Omega_{1}$ reflete o grau de poder de barganha dos trabalhadores e $\Omega_{2}$, o grau de indexação às expectativas de preços. $\Psi_{1}$ e $\Psi_{2}$ podem ser interpretados de forma análoga para o caso das firmas.

Neste trabalho, supomos que o poder de barganha dos trabalhadores depende da taxa de desemprego ${ }^{3}$. Dessa forma, quanto menor a taxa de desemprego, maior é a capacidade de os trabalhadores atingirem seus objetivos. A validade desta hipótese será testada por meio da significância do parâmetro da taxa de desemprego na equação salarial. Além disso, supõe-se que existem outros custos além dos salários, constituídos por insumos importados, e o mark-up incide sobre todos os custos.

Esse modelo pode ser refinado de diversas formas ${ }^{4}$, porém, como coloca Lavoie (1992) tais mudanças não alteram a essência do modelo, baseado na existência de conflito distributivo. Duas questões interessantes são: i) a possibilidade de um conflito indireto entre rentistas e assalariados que acontece quando se supõe que a taxa de lucro segue a taxa de juros (devido ao custo financeiro e/ou custo oportunidade do capital) ${ }^{5}$, nesse caso as margens de lucro seguem a taxa de lucro quando o grau de utilização é normal; e ii) a possibilidade de um conflito intersalarial (wage-wage).

Embora adotemos esse marco teórico, este trabalho não é uma tentativa de estimar um modelo específico da classe dos modelos de conflito distributivo, mas sim de estimar o impacto estatístico dos diferentes tipos de inflação sugeridos na tipologia proposta na literatura pós-keynesiana (ver Sicsú, 2003), de forma

(3) Considera-se suficiente para a explicação do aumento do poder de barganha dos trabalhadores e consequentemente dos salários na década de 2000 no Brasil e torna dispensável o uso de variáveis institucionais sobre a configuração do mercado de trabalho como aquelas adotadas em Setterfield (2004), afastando, assim, possíveis problemas de multicolinearidade. Isso porque, ao contrário do que ocorreu nos Estados Unidos na década de 1990, a diminuição da taxa de desemprego no Brasil esteve associada a uma melhora institucional do mercado de trabalho com aumento da formalização e um governo mais atento às reivindicações dos sindicatos. Portanto, as duas variáveis permitiram um aumento do poder de barganha dos trabalhadores. Nos Estados Unidos as variáveis foram em direções contrárias, a queda da taxa de desemprego não estimulou aumento dos salários, assim, nesse caso, a adoção das variáveis explicativas institucionais se faz necessária.

(4) Drummond e Porcile (2010) desenvolvem um modelo macrodinâmico para a economia brasileira, na qual a inflação é determinada a partir de modelo de conflito distributivo para o caso de uma economia aberta. Nesta formulação, os trabalhadores aceitam menor participação na renda quando o câmbio (real) valoriza, uma vez que parte da cesta de consumo é composta por bens importados. Uma relação negativa entre salário real e câmbio é encontrada em Bastos e Braga (2010).

(5) Uma evidência empírica dessa relação foi encontrada em Bastos e Braga (2010). 
compatível com os fundamentos gerais da literatura dos modelos de conflito distributivo.

A maioria dos trabalhos recentes de modelo de conflito distributivo reduz as duas equações de preço e salário em uma equação de curto prazo da inflação de produto, para encontrar uma formulação da "curva de Phillips" compatível com as hipóteses de conflito distributivo ${ }^{6}$. Neste trabalho, optou-se por estimar um modelo estrutural que explicita a equação da inflação salarial como variável dependente. Uma forma estrutural de equações de preço e salário foi sugerida por Fair (2008), em virtude da possibilidade de explicitar as interações entre salários e preços. $\mathrm{O}$ autor encontrou que tal formulação apresenta estimativas com melhor capacidade preditiva do que a forma reduzida da variação dos preços.

Esta forma estrutural foi adotada em outros trabalhos empíricos da década de 2000 para modelar a inflação nos Estados Unidos em contraposição à forma reduzida, amplamente adotada nas décadas anteriores (ver Eller; Gordon, $2003)^{7}$. Ocorre que ao longo da década de 1990 a forma reduzida passou a apresentar contínuos erros de previsão, numa conjuntura de diminuição da taxa de desemprego com baixa ou nenhuma resposta da inflação de produto, devido ao lento crescimento dos salários nominais frente ao ritmo de crescimento da produtividade.

O modelo econométrico utilizado será um VAR-X (metodologia de Vetores Autorregressivos com Variáveis Exógenas), com $p$ defasagens para as variáveis endógenas e $q$ defasagens para as exógenas, para lidar com a simultaneidade das séries de inflação de produto e de salário e ao mesmo tempo incluir variáveis exógenas a ambos. $\mathrm{O}$ símbolo $\Delta$ representa variações percentuais:

$$
Y_{t}=\Omega_{1} Y_{t-1}+\Omega_{2} Y_{t-2}+\ldots+\Omega_{p} Y_{t-p}+\Psi_{0} X_{t}+\Psi_{1} X_{t-1}+\Psi_{2} X_{t-2}+\ldots \Psi_{q} X_{t-q}+\mu_{t}
$$

Os preços e salários serão considerados variáveis endógenas compondo o vetor $Y$.

$$
Y_{t}=\left[\pi_{t}, \Delta W_{t}\right]
$$

$X$ é um vetor de variáveis exógenas:

(6) Alguns autores como Pollin (2002) enfatizam o papel de fatores institucionais como determinantes para a capacidade dos trabalhadores de igualar a participação desejada na renda nacional com a efetivamente ocorrida. Na mesma linha, Setterfield (2004) inclui uma série de variáveis exógenas que representam fatores institucionais que afetam o processo de fixação de salários e preços, como o grau de sindicalização dos trabalhadores e a possibilidade de deslocalização por parte das firmas em busca de salários mais baixos em outros países.

(7) Outros autores adotaram a forma estrutural da Curva de Phillips como Flaschel, Kauermann e Semmler (2007), Staiger, Stock e Watson (2001). 


$$
X_{t}=\left[\Delta \varepsilon_{t}, \Delta P_{t}^{*}, u_{t}, \Delta T_{t}, \Delta W_{\min }\right]
$$

' $\Omega$ ' e ' $\Psi$ ' são as matrizes de coeficientes a serem estimados e $\mu_{t}$ é um vetor de inovações que pode ser correlacionado no tempo contemporâneo, mas não com o passado nem com as variáveis do lado direito da equação. A inflação importada foi decomposta para permitir estimar o impacto separado dos preços internacionais $P_{t}^{*}$ e da taxa de câmbio $\left(\varepsilon_{t}\right)$. Como proxy dos preços internacionais foram considerados apenas os preços das commodities. No caso das equações para as componentes do Índice de Preços ao Consumidor Amplo (IPCA), outras variáveis foram incluídas e suas significâncias, testadas; quais sejam, a variação percentual do salário mínimo (SM) $\left(W_{\min }\right)$, uma dummy para mudanças no Imposto sobre Produtos Industrializados (IPI) $\left(T_{t}\right)$ e a inflação segundo o Índice Geral de Preços do Mercado (IGP-M), defasada em 12 meses, como indicador do grau de indexação da economia.

Estamos explicitando a inflação salarial no modelo mas não a inflação de lucro pela falta de disponibilidade dos dados. Interpretamos então que as variações das margens de lucro estão implícitas na primeira equação. Assim, ao inserirmos a variável de demanda na equação do produto, podemos testar se existe inflação de demanda ou se é válida a hipótese levantada por alguns autores pós-keynesianos de que o crescimento da demanda facilita o repasse dos aumentos de custo aos preços, permitindo aumentos pró-cíclicos das margens de lucro em setores oligopolizados (ver Lavoie, 1992).

É importante notar que essa formulação fundamentada em modelos de conflito distributivo não é compatível com as formulações tradicionais da curva de Phillips (seja a versão aceleracionista, neokeynesiana ou triangular da Curva de Phillips). Em primeiro lugar porque não existe qualquer tentativa de estimar uma taxa de desemprego que não acelere a inflação -, taxa de não aceleração da inflação de desemprego - Non-Accelerating Inflation Rate of Unemployment (NAIRU). Tal conceito foi criticado por inúmeros autores tanto do ponto de vista teórico, quanto empírico (Staiger; Stock; Watson, 1996). Em segundo lugar, porque as variáveis de custo não são meros "choques de oferta", uma vez que não são preços relativos, mas sim variações percentuais dos próprios custos nominais que podem ter efeitos permanentes e duradouros sobre a inflação.

Foi considerado também, como variável exógena, um indicador de excesso de demanda. Para tal, foram utilizados como indicadores o grau de utilização da capacidade produtiva na indústria e a taxa geral de desemprego. A taxa de desemprego é sugerida por Fair (2008) como o melhor indicador de demanda para a equação de preços. No que se refere ao papel das expectativas inflacionárias, foi considerada uma curva do tipo backward looking devido à enorme dificuldade 
reportada na literatura de se achar suporte empírico a formulações do tipo forward looking da curva de Phillips. Esse tipo de modelagem é compatível tanto com especificações de expectativas do tipo adaptativas (porém ajustáveis), como racionais (ver Fuhrer, 1997; Eller; Gordon, 2003).

Além das estimativas agregadas, foram considerados modelos para as componentes do IPCA nas seguintes categorias: monitorados (que incluem os serviços públicos e outros preços administrados) e livres, sendo estes últimos subdivididos em bens de consumo duráveis, não duráveis e semiduráveis. A descrição de cada categoria é realizada no anexo no final do texto. Para estas desagregações foi testada a necessidade de se utilizar os modelos estruturais, a partir de testes de exogeneidade, para inferir se o salário médio pode ser considerado uma variável exógena às variações dos preços de cada categoria de bens e serviços. Neste caso, foram utilizados modelos uniequacionais do tipo ARMAX para os preços livres e GARCH para os preços monitorados. A opção pelo modelo GARCH no caso dos preços monitorados ocorreu devido ao efeito ARCH observado no modelo ARMAX inicialmente testado.

\section{Processo de modelagem e resultados das estimativas}

Foram realizados três testes para verificar a existência de raiz unitária, quais sejam, o Augmented Dickey-Fuller (ADF), Kwiatkowski, Phillips, Schmidt, e Shin (KPSS), e o teste de Sargan-Bhargava modificado por Ng e Perron $(\mathrm{MSB})^{8}$. Para as séries com comportamento sazonal, foi levado em consideração adicionalmente o resultado do teste ADF na presença de dummies sazonais. Segundo a análise de autocorrelação, as séries que apresentaram sazonalidade foram os serviços (com uma sazonalidade marcante), os semiduráveis (com correlações de meio período, $6,12,18$, e 24, indicando possivelmente o efeito das coleções de verão/inverno para o vestuário) e os monitorados (com uma sazonalidade suave). De maneira geral, a interpretação dos resultados deve levar o curto tamanho das séries analisadas em consideração.

Os resultados do teste $\mathrm{ADF}$ indicaram a rejeição da hipótese de raiz unitária; para o caso dos semiduráveis e dos serviços, isto se mostrou verdadeiro somente quando levada em consideração a presença de dummies sazonais aditivas. A análise do correlograma corroborou os resultados do teste $\mathrm{ADF}$, a não ser no caso dos semiduráveis, cuja dinâmica pareceu indicar a presença de uma raiz unitária sazonal. O teste KPSS mostrou resultado diferente no caso dos duráveis, dos monitorados e da variação salarial. Já o MSB indicou resultado diferente ao do

(8) A tabela não está exposta no trabalho por limitações de espaço, mas é disponibilizada por meio de contato eletrônico. 
ADF nos casos dos monitorados e variação salarial. No caso da variação salarial, pode pesar a mudança de metodologia da série ocorrida em 2003.

Tendo em vista os resultados, foram considerados modelos que assumem estacionariedade das séries agregadas e componentes com exceção dos bens de consumo semiduráveis. Posteriormente foram realizados testes de raiz unitária nos resíduos, para assegurar a robustez dos resultados e afastar problemas de "regressões espúrias".

As estimativas para o modelo VAR-X para a inflação agregada estão expostas no Quadro 1. Os critérios de informação de Schwarz e de Hannan-Quinn indicaram uma defasagem, VAR (1), enquanto que o critério de Akaike, o critério FPE (Final prediction error criterion) e o teste de hipótese de razão de maximaverossimilhança (Likelihood ratio test criterion) três defasagens, VAR (3). Em virtude da mudança de metodologia da Pesquisa Mensal de Emprego do Instituto Brasileiro de Geografia e Estatística (PME/IBGE), foi estimado também um modelo com as séries restritas ao período de 2003 a 2010, considerando uma versão parcimoniosa devido ao pequeno tamanho das séries. Foi ainda incluída a inflação do produto segundo o IPCA e segundo o IGP-M na defasagem 12 para levar em conta possíveis efeitos sazonais da inflação do produto e captar uma possível reação defasada dos salários aos índices de preços.

Os testes para os resíduos diagnosticaram estacionariedade, ausência de autocorrelação, porém presença de heterocedasticidade. Reestimamos os sistemas com a utilização do estimador de mínimos quadrados ponderados para a obtenção de desvios-padrão robustos.

Os resultados dos coeficientes indicam que a inflação salarial não foi significativa na explicação da inflação de produto no caso do modelo 1 , porém foi significativa no caso do modelo 2. Ao mesmo tempo, a inflação de produto foi significativa na equação da variação salarial, na defasagem 12, no Modelo 1 com alto coeficiente. Apesar de o teste de Wald indicar que a inflação salarial e de produto podem ser consideradas exógenas uma a outra no modelo 1, existiu um grau de reação dos salários à inflação do ano anterior, não captada diretamente no teste pelo fato de ter sido incluída como variável exógena. No caso do modelo 2, o resultado do teste indicou que somente a variação salarial pode ser considerada fracamente exógena. Dessa forma, apesar dessas diferenças, influenciadas pela diferença entre o período das amostras, existem indícios de uma interação entre as duas variáveis com os preços sendo afetados por salários e os últimos reagindo defasadamente à inflação de produto para recompor perdas de poder de compra. 
Quadro 1

ARMAX da Inflação dos bens de consumo semi-duráveis (diferenciado sazonalmente)

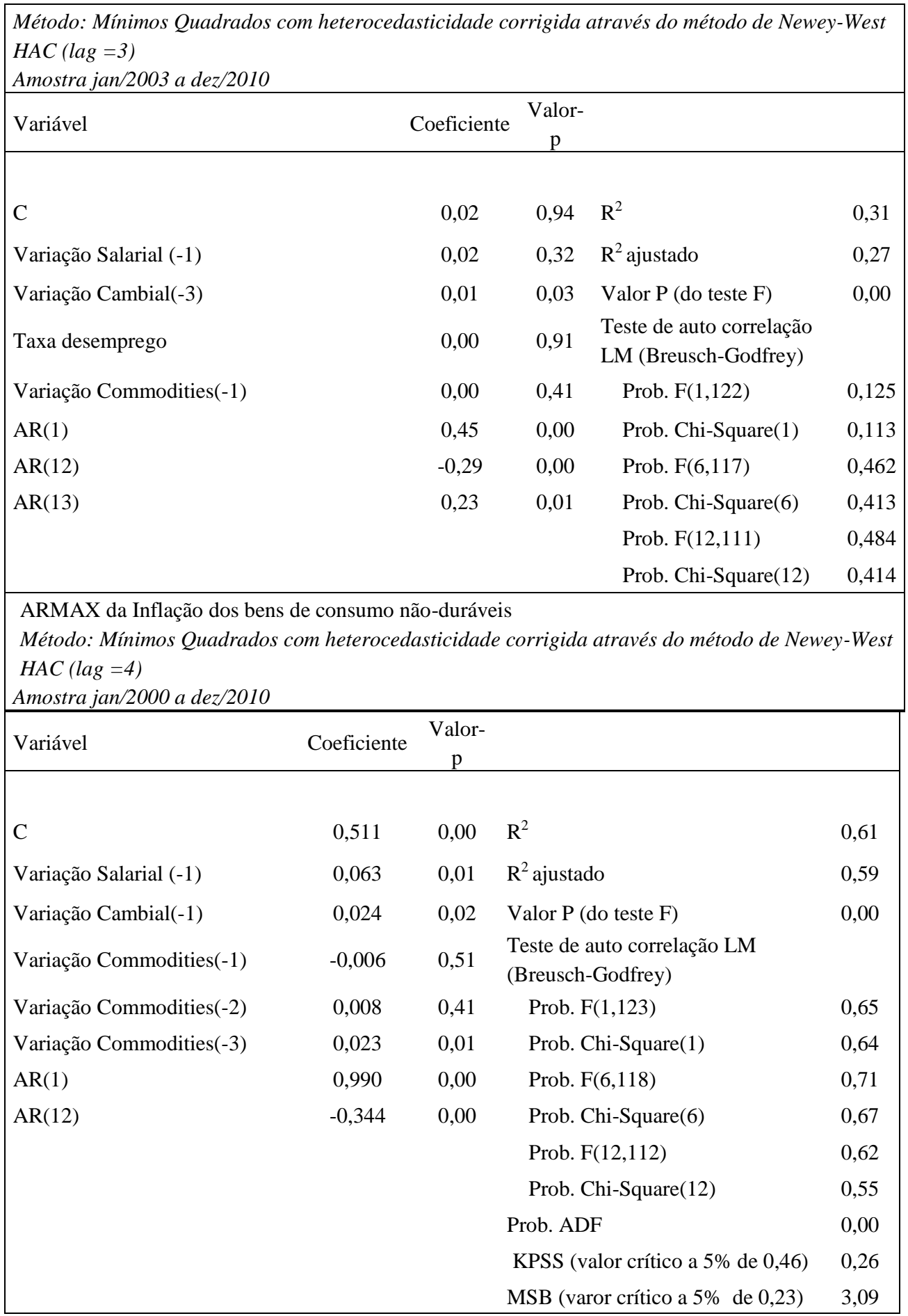


Os testes indicaram que o IGP-M não é um indexador significativo para a inflação de produto agregada segundo o IPCA, pois seu coeficiente ficou negativo no caso do modelo 1, e sem significância estatística no caso do modelo 2. A inércia, contudo, foi alta (entre 0,70 e 0,80 ), indicando um processo de autoalimentação da inflação. Coeficientes menores que a unidade, porém, não justificam a adoção de modelos aceleracionistas da Curva de Phillips para a inflação brasileira, pois estatisticamente tal modelo leva a uma superdiferenciação não necessária da série de inflação.

A variação cambial e de preços de commodities se mostrou significativa quando inseridas com uma defasagem do mês anterior. Essas são as duas variáveis mais robustas na explicação da inflação, com significância muito alta em todas as versões estimadas do modelo VAR. Nota-se que a variação cambial teve coeficiente superior ao coeficiente associado à variação das commodities. Os indicadores de demanda não foram significativos na equação da inflação de produto. Na equação dos salários, a taxa de desemprego foi significativa como variável exógena apenas no nível, e não na variação. O grau de utilização da capacidade produtiva não foi significativo em nenhuma das duas equações.

Replicamos então essa modelagem para o caso específico de cada componente separadamente, adotando as mesmas variáveis exógenas. No caso dos preços monitorados pelo governo, devido à natureza da série, não foi realizada uma tentativa de estimação a partir de um modelo teórico econômico, mas uma tentativa de caráter puramente estatístico de identificar as variáveis que tiveram impacto nas regras de reajuste estipuladas e adotadas. Nesse caso, foi encontrada evidência de um efeito ARCH nos resíduos de uma equação do tipo ARMAX com as mesmas variáveis exógenas do VAR-X do IPCA (Quadro 2).

Quadro 2

Teste para efeito ARCH dos preços monitorados

\begin{tabular}{|ll|}
\hline Prob. F(12,119) & 0,01 \\
Prob. Chi-Square(12) & 0,02 \\
Prob. F(2,129) & 0,00 \\
Prob. Chi-Square(2) & 0,00 \\
\hline & \\
\hline Prob. F(12,119) & 0,84 \\
Prob. Chi-Square(12) & 0,84 \\
Prob. F(2,129) & 0,47 \\
Prob. Chi-Square(2) & 0,46 \\
\hline
\end{tabular}

A partir do modelo ARMAX para a Inflação mensal 
Esse efeito de variância condicionada não constante foi modelado a partir de um GARCH-M com a inclusão da variância condicionada na equação principal (esperança condicionada) do GARCH. Os testes indicaram significância até a defasagem 4 do termo GARCH, porém o GARCH-M(1,1) se mostrou suficiente para eliminar o efeito ARCH dos resíduos (quadro 3). A variância mostrou-se significativa como variável explicativa na equação da esperança condicionada. $\mathrm{O}$ teste Bera Jarque indicou que a distribuição condicional normal para os resíduos foi rejeitada, desta forma, foi considerada uma distribuição generalizada dos resíduos (GED).

Quadro 3

GARCH Inflação mensal dos preços monitorados

\begin{tabular}{|c|c|c|c|c|}
\hline \multicolumn{5}{|c|}{$\begin{array}{l}\text { Amostra jan/2000 a dez/2010 } \\
\text { Método: ML - ARCH (Marquardt) - Distribuição Generalizada dos Erros }(\text { GED) } \\
\text { Presample variance: backcast (parameter }=0.7)\end{array}$} \\
\hline Equação da Esperança condicionada & Coeficiente & Valo & or-p & \\
\hline GARCH & 0,21 & 0,04 & & \\
\hline $\mathrm{C}$ & 0,25 & 0,00 & & \\
\hline Variação Salarial (-1) & 0,01 & 0,49 & & \\
\hline Variação Cambial(-1) & 0,01 & 0,00 & & \\
\hline Variação Commodities(-1) & 0,02 & 0,00 & & \\
\hline $\operatorname{IGPM}(-12)$ & 0,04 & 0,11 & $\mathrm{R}^{2}$ & 0,24 \\
\hline $\operatorname{AR}(1)$ & 0,27 & 0,00 & $\mathrm{R}^{2}$ ajustado & 0,15 \\
\hline $\mathrm{aR}(1)$ & 0,09 & 0,03 & valor $\mathrm{p}$ do Bera-Jarque & 0,00 \\
\hline Equação da Variância Condicionada & & & Teste para o efeito ARC & \\
\hline $\mathrm{C}$ & 0,00 & 0,70 & Prob. F(12,119) & 0,84 \\
\hline Componente ARCH(-1) & 0,10 & 0,11 & Prob. Chi-Square(12) & 0,84 \\
\hline Componente GARCH(-1) & 0,89 & 0,00 & Prob. F(2,129) & 0,47 \\
\hline Parâmetro do GED & 0,79 & 0,00 & Prob. Chi-Square(2) & 0,46 \\
\hline
\end{tabular}

No caso das séries de duráveis, não duráveis e serviços, os testes de Wald de exogeneidade (Quadro 4) indicaram que a inflação salarial pode ser considerada uma variável exógena na equação da inflação desses preços. Estes resultados permitiram a adoção de modelos uniequacionais. A alternativa de modelagem adotada foi o ARMAX. 
Quadro 4

Teste de bloco exogeneidade de Wald ${ }^{(*)}$

\begin{tabular}{|lc|}
\hline Amostra jan/2003 a dez/2010 & valor p \\
\hline Excluida a variação salarial da equação dos duráveis & 0.4173 \\
Excluida os duráveis da equação da variação salarial & 0.5640 \\
\hline Excluida a variação salarial da Inflação dos não-duráveis & 0.1293 \\
Excluida a inflação dos não-duráveis da equação da variação salarial & 0.3884 \\
\hline * Aplicados a VAR(1) com exógenas. & \\
\hline Excluida a variação salarial da Inflação dos serviços & 0.4425 \\
Excluida a inflação dos serviços da equação da variação salarial & 0.4688 \\
\hline
\end{tabular}

* Aplicados a $\operatorname{VAR}(3)$ com exógenas.

O Quadro 5 mostra os resultados do ARMAX para o período de 2003 a 2010 para o caso dos bens duráveis. Os resultados mostram forte significância da variação cambial e da variação dos preços das commodities enquanto os coeficientes da taxa de desemprego e da variação salarial não apresentaram significância estatística. Foi testada, adicionalmente, a relevância de uma dummy para mudanças na alíquota do IPI para alguns dos bens cujos preços são componentes do índice. Esta não foi significativa, o que pode ser relacionado ao fato de que as isenções não foram generalizadas a todos os bens duráveis. Um modelo mais parcimonioso foi considerado em seguida. Como a variação salarial não se mostrou significativa, pôde-se trabalhar com o período mais amplo, de 2000 a 2010. Os testes de diagnóstico indicaram resíduos estacionários e não autocorrelacionados, porém heterocedásticos. Por isso, foi adotado o método de Newey-West para a estimação de desvios-padrão robustos.

Quadro 5

ARMAX da Inflação dos bens de consumo duráveis

\begin{tabular}{|c|c|c|c|c|}
\hline \multicolumn{5}{|l|}{ Amostra jan/2003 a dez/2010 } \\
\hline Variável & Coeficiente & Valor-p & & \\
\hline $\mathrm{C}$ & 0,278 & 0,49 & $\mathrm{R}^{2}$ & 0,56 \\
\hline Variação Salarial (-1) & 0,005 & 0,86 & $\mathrm{R}^{2}$ ajustado & 0,53 \\
\hline Variação Cambial(-1) & 0,023 & 0,00 & Valor P (do teste F) & 0,00 \\
\hline Variação Commodities(-1) & 0,017 & 0,00 & \multicolumn{2}{|c|}{$\begin{array}{l}\text { Teste de auto correlação LM (Breusch- } \\
\text { Godfrey) }\end{array}$} \\
\hline Taxa desemprego & $-0,028$ & 0,53 & Prob. F(1,88) & 0,13 \\
\hline $\mathrm{AR}(1)$ & 0,681 & 0,00 & Prob. Chi-Square(1) & 0,11 \\
\hline \multirow[t]{6}{*}{$\operatorname{AR}(12)$} & 0,132 & 0,01 & Prob. F(2,87) & 0,28 \\
\hline & & & Prob. Chi-Square(2) & 0,25 \\
\hline & & & Prob. F(6,83) & 0,59 \\
\hline & & & Prob. Chi-Square(6) & 0,53 \\
\hline & & & Prob. F(12,77) & 0,69 \\
\hline & & & Prob. Chi-Square(12) & 0,60 \\
\hline
\end{tabular}

Continua... 
Quadro 5 - Continuação

\begin{tabular}{|c|c|c|c|c|}
\hline \multicolumn{5}{|c|}{ Modelo Parcimonioso (Amostra jan/2000 a dez/2010) } \\
\hline Variável & Coeficiente & Valor-p & & \\
\hline $\mathrm{C}$ & 0,192 & 0,114 & $\mathrm{R}^{2}$ & 0,52 \\
\hline Variação Cambial(-1) & 0,019 & 0,088 & $\mathrm{R}^{2}$ ajustado & 0,50 \\
\hline Variação Commodities(-1) & 0,012 & 0,023 & Valor P (do teste F) & 0,00 \\
\hline $\operatorname{AR}(1)$ & 0,668 & 0,000 & \multicolumn{2}{|c|}{$\begin{array}{l}\text { Teste de auto correlação LM (Breusch- } \\
\text { Godfrey) }\end{array}$} \\
\hline \multirow[t]{9}{*}{$\operatorname{AR}(12)$} & 0,090 & 0,024 & Prob. F(1,126) & 0,97 \\
\hline & & & Prob. Chi-Square(1) & 0,97 \\
\hline & & & Prob. F $(6,121)$ & 0,69 \\
\hline & & & Prob. Chi-Square(6) & 0,66 \\
\hline & & & Prob. F(12,115) & 0,78 \\
\hline & & & $\begin{array}{l}\text { Prob. Chi- } \\
\text { Square(12) }\end{array}$ & 0,74 \\
\hline & & & Prob. ADF & 0,00 \\
\hline & & & $\begin{array}{l}\text { KPSS (valor crítico a } \\
5 \% \text { de } 0,46 \text { ) }\end{array}$ & 0,40 \\
\hline & & & $\begin{array}{l}\text { MSB (valor crítico a } \\
5 \% \text { de } 0,23 \text { ) }\end{array}$ & 0,61 \\
\hline
\end{tabular}

Método: Mínimos Quadrados com heterocedasticidade corrigida através do método de Newey-West HAC $(\operatorname{lag}=3)$

No caso dos bens não duráveis existe uma defasagem maior de resposta da variação dos preços das commodities aos preços ao consumidor, uma vez que o coeficiente só é significativo na defasagem 3 (Quadro 6). A variação cambial é fortemente significativa. A variação salarial também é significativa, provavelmente devido ao item Alimentação fora do domicílio, que é uma categoria que pode ser considerada, em certa medida, um serviço.

Quadro 6

ARMAX da Inflação dos bens de consumo não-duráveis

\begin{tabular}{|lcclc|}
\hline $\begin{array}{l}\text { Método: Mínimos Quadrados com heterocedasticidade corrigida através do método de Newey-West } \\
\text { HAC (lag =3) } \\
\text { Amostra jan/2003 a dez/2010 }\end{array}$ & Coeficiente & Valor-p \\
\hline Variável & 0,688 & 0,20 & $\mathrm{R}^{2}$ & 0,55 \\
\hline C & 0,056 & 0,03 & $\mathrm{R}^{2}$ ajustado & 0,51 \\
Variação Salarial (-1) & 0,022 & 0,02 & Valor P (do teste F) & 0,00 \\
Variação Cambial(-1) & 0,001 & 0,93 & Teste de auto correlação LM \\
Variação Commodities(-1) & 0,004 & 0,67 & (Breusch-Godfrey) & Prob. F(1,86) \\
Variação Commodities(-2) & 0,026 & 0,01 & Prob. Chi-Square(1) & 0,40 \\
Variação Commodities(-3) & $-0,028$ & 0,59 & Prob. F(6,81) & 0,22 \\
Taxa desemprego & 0,801 & 0,00 & Prob. Chi-Square(6) & 0,17 \\
AR(1) & $-0,229$ & 0,05 & Prob. F(12,75) & 0,06 \\
AR(12) & \multicolumn{5}{r}{ Prob. Chi-Square(12) } & 0,04 \\
\hline
\end{tabular}




\begin{tabular}{|c|c|c|c|c|}
\hline \multicolumn{5}{|c|}{ Modelo Parcimonioso (amostra jan/2000 a dez/2010)* } \\
\hline Variável & Coeficiente & Valor-p & & \\
\hline $\mathrm{C}$ & 0,511 & 0,00 & $\mathrm{R}^{2}$ & 0,61 \\
\hline Variação Salarial (-1) & 0,063 & 0,01 & $\mathrm{R}^{2}$ ajustado & 0,59 \\
\hline Variação Cambial(-1) & 0,024 & 0,02 & Valor P (do teste F) & 0,00 \\
\hline Variação Commodities(-1) & $-0,006$ & 0,51 & \multicolumn{2}{|c|}{$\begin{array}{l}\text { Teste de auto correlação LM } \\
\text { (Breusch-Godfrey) }\end{array}$} \\
\hline Variação Commodities(-2) & 0,008 & 0,41 & Prob. F(1,123) & 0,65 \\
\hline Variação Commodities(-3) & 0,023 & 0,01 & Prob. Chi-Square(1) & 0,64 \\
\hline $\mathrm{AR}(1)$ & 0,990 & 0,00 & Prob. $F(6,118)$ & 0,71 \\
\hline \multirow[t]{6}{*}{$\operatorname{AR}(12)$} & $-0,344$ & 0,00 & Prob. Chi-Square(6) & 0,67 \\
\hline & & & Prob. F(12,112) & 0,62 \\
\hline & & & Prob. Chi-Square(12) & 0,55 \\
\hline & & & Prob. ADF & 0,00 \\
\hline & & & $\begin{array}{l}\text { KPSS (valor crítico a } \\
5 \% \text { de } 0,46 \text { ) }\end{array}$ & 0,26 \\
\hline & & & $\begin{array}{l}\text { MSB (varor crítico a } \\
5 \% \text { de } 0,23 \text { ) }\end{array}$ & 3,09 \\
\hline
\end{tabular}

*Newey-West HAC (lag =4)

No caso de serviços foram incluídas as defasagens individuais 12 e 24 da série de serviços para lidar com sazonalidade da série (Quadro 7). O teste de Breusch-Godfrey (BG) também indicou heterocedasticidade. Essa categoria tem natureza bastante diferenciada das demais porque é a única em que a variação cambial e a variação dos preços das commodities não tiveram impacto significativo. Além disso, a variação salarial apareceu de forma bastante significativa na defasagem 12.

Essa influência defasada em um ano dos salários no preço dos serviços pode estar relacionda ao caráter extremamente sazonal da série. Outra interpretação possível parece sugerir o impacto do SM como indexador, com os reajustes anuais pressionando os preços dos serviços no ano seguinte. A influência do SM, contudo, foi mais complicada de ser captada, pois se trata de uma série temporal extremamente problemática para ser incluída em qualquer modelo econométrico. Isto porque além de os reajustes serem concentrados em apenas um mês de cada ano, o mês de reajuste variou de ano para ano. A análise gráfica do correlograma cruzado indicou significância entre a variação mensal do SM e a inflação de serviços em defasagens pouco comuns (10 e 22). As correlações em defasagens diferentes das tradicionais podem ser resultado destas alterações dos reajustes do salário SM ao longo dos últimos anos. 
Quadro 7

ARMAX da Inflação dos serviços

\begin{tabular}{|c|c|c|c|c|}
\hline \multicolumn{5}{|c|}{$\begin{array}{l}\text { Método: Mínimos Quadrados } \\
\text { White } \\
\text { Amostra jan/2003 a dez/2010 }\end{array}$} \\
\hline Variável & Coeficiente & Valor-p & & \\
\hline $\mathrm{C}$ & 0,921 & 0,079 & $\mathrm{R}^{2}$ & 0,67 \\
\hline Variação Salarial (-1) & 0,019 & 0,376 & $\mathrm{R}^{2}$ ajustado & 0,65 \\
\hline Variação Salarial (-12) & 0,030 & 0,029 & Valor P (do teste F) & 0,00 \\
\hline Taxa desemprego & $-0,013$ & 0,622 & $\begin{array}{l}\text { Teste de auto correlação LM } \\
\text { (Breusch-Godfrey) }\end{array}$ & \\
\hline Variação Cambial(-1) & 0,005 & 0,270 & Prob. F(1,109) & 0,28 \\
\hline Variação Commodities(-1) & 0,002 & 0,486 & Prob. Chi-Square(1) & 0,26 \\
\hline IGPM(-12) & 0,019 & 0,258 & Prob. F(6,104) & 0,77 \\
\hline $\operatorname{AR}(1)$ & 0,087 & 0,204 & Prob. Chi-Square(6) & 0,72 \\
\hline $\operatorname{AR}(12)$ & 0,658 & 0,000 & Prob. F(12,98) & 0,52 \\
\hline \multirow[t]{2}{*}{ AR (24) } & 0,165 & 0,160 & Prob. Chi-Square(12) & 0,42 \\
\hline & & & $\begin{array}{l}\text { Teste de heterocedasticidade } \\
\text { de White (antes da correção) } \\
\text { Prob. F(54,65) } \\
\text { Prob. Chi-Square }(54)\end{array}$ & $\begin{array}{l}0,00 \\
0,02 \\
\end{array}$ \\
\hline \multicolumn{5}{|l|}{ Amostra jan/2000 a dez/2010 } \\
\hline \multirow[t]{2}{*}{ Variável } & Coeficiente & Valor-p & & \\
\hline & & & $\mathrm{R}^{2}$ & 0,67 \\
\hline $\mathrm{C}$ & 0,855 & 0,14 & $\mathrm{R}^{2}$ ajustado & 0,65 \\
\hline Variação Salarial (-1) & 0,021 & 0,30 & Valor P (do teste F) & 0,00 \\
\hline Variação Salarial (-12) & 0,031 & 0,03 & $\begin{array}{l}\text { Teste de auto correlação LM } \\
\text { (Breusch-Godfrey) }\end{array}$ & \\
\hline $\operatorname{AR}(1)$ & 0,092 & 0,18 & Prob. F(1,113) & 0,14 \\
\hline $\operatorname{AR}(12)$ & 0,663 & 0,00 & Prob. Chi-Square(1) & 0,13 \\
\hline \multirow[t]{15}{*}{$\operatorname{AR}(24)$} & 0,156 & 0,13 & Prob. F(2,112) & 0,28 \\
\hline & & & Prob. Chi-Square(2) & 0,26 \\
\hline & & & Prob. F(6,108) & 0,72 \\
\hline & & & Prob. Chi-Square(6) & 0,68 \\
\hline & & & Prob. F(12,102) & 0,60 \\
\hline & & & Prob. Chi-Square(12) & 0,54 \\
\hline & & & $\begin{array}{l}\text { Teste de heterocedasticidade de } \\
\text { Breusch-Pagan-Godfrey }\end{array}$ & \\
\hline & & & Prob. $F(2,117)$ & 0,85 \\
\hline & & & Prob. Chi-Square(2) & 0,85 \\
\hline & & & $\begin{array}{l}\text { Teste de heterocedasticidade } \\
\text { de White (antes da correção) }\end{array}$ & \\
\hline & & & Prob. F(20,99) & 0,01 \\
\hline & & & Prob. Chi-Square(20) & 0,02 \\
\hline & & & Prob. ADF & 0,00 \\
\hline & & & $\begin{array}{l}\text { KPSS (valor crítico a } 5 \% \text { de } \\
0,46)\end{array}$ & 0,24 \\
\hline & & & $\begin{array}{l}\text { MSB (varor crítico a } 5 \% \text { de } \\
0,23 \text { ) }\end{array}$ & 0,21 \\
\hline
\end{tabular}


Para a série de bens de consumo semiduráveis, optou-se pela transformação da série a partir da diferenciação sazonal, necessária para a obtenção de resíduos bem comportados. Nesse caso houve a especificação de um modelo com sazonalidade multiplicativa, de forma que a interação de um AR(1) e o AR(1) sazonal levaram a um coeficiente significativo na defasagem 13. A única variável exógena significativa foi a variação cambial, porém, ainda assim, somente na defasagem 3. Vale lembrar que dentre as categorias analisadas esta é a que apresenta menor peso no IPCA agregado.

Quadro 8

ARMAX da Inflação dos bens de consumo semi-duráveis (diferenciado sazonalmente)

\begin{tabular}{|c|c|c|c|c|}
\hline \multicolumn{5}{|l|}{$\begin{array}{l}\text { Método: Mínimos Quadrados c } \\
\text { West HAC (lag =3) } \\
\text { Amostra jan/2003 a dez/2010 }\end{array}$} \\
\hline Variável & Coeficiente & Valor-p & & \\
\hline $\mathrm{C}$ & 0,02 & 0,94 & $\mathrm{R}^{2}$ & 0,31 \\
\hline Variação Salarial (-1) & 0,02 & 0,32 & $\mathrm{R}^{2}$ ajustado & 0,27 \\
\hline \multirow[t]{2}{*}{ Variação Cambial(-3) } & 0,01 & 0,03 & Valor P (do teste F) & 0,00 \\
\hline & & & Teste de auto correlação & \\
\hline Taxa desemprego & 0,00 & 0,91 & LM (Breusch-Godfrey) & \\
\hline Variação Commodities(-1) & 0,00 & 0,41 & Prob. F(1,122) & 0,125 \\
\hline $\mathrm{AR}(1)$ & 0,45 & 0,00 & Prob. Chi-Square(1) & 0,113 \\
\hline $\mathrm{AR}(12)$ & $-0,29$ & 0,00 & Prob. F(6,117) & 0,462 \\
\hline \multirow[t]{3}{*}{$\operatorname{AR}(13)$} & 0,23 & 0,01 & Prob. Chi-Square(6) & 0,413 \\
\hline & & & Prob. F(12,111) & 0,484 \\
\hline & & & Prob. Chi-Square(12) & 0,414 \\
\hline \multicolumn{5}{|c|}{$\begin{array}{l}\text { ARMAX da Inflação dos bens de consumo não-dur } \\
\text { Método: Mínimos Quadrados com heterocedasticic } \\
\text { West HAC (lag =4)Amostra jan/2000 a dez/2010 }\end{array}$} \\
\hline Variável & Coeficiente & Valor-p & & \\
\hline $\mathrm{C}$ & 0,511 & 0,00 & $\mathrm{R}^{2}$ & 0,61 \\
\hline \multirow{2}{*}{$\begin{array}{l}\text { Variação Salarial (-1) } \\
\text { Variação Cambial(-1) }\end{array}$} & 0,063 & 0,01 & $\mathrm{R}^{2}$ ajustado & 0,59 \\
\hline & 0,024 & 0,02 & Valor P (do teste F) & 0,00 \\
\hline & & & Teste de auto correlação & \\
\hline \multirow{5}{*}{$\begin{array}{l}\text { Variação Commodities(-1) } \\
\text { Variação Commodities(-2) } \\
\text { Variação Commodities(-3) } \\
\text { AR(1) } \\
\text { AR(12) }\end{array}$} & $-0,006$ & 0,51 & LM (Breusch-Godfrey) & \\
\hline & 0,008 & 0,41 & Prob. $F(1,123)$ & 0,65 \\
\hline & 0,023 & 0,01 & Prob. Chi-Square(1) & 0,64 \\
\hline & 0,990 & 0,00 & Prob. $F(6,118)$ & 0,71 \\
\hline & $-0,344$ & 0,00 & Prob. Chi-Square(6) & 0,67 \\
\hline & & & Prob. F(12,112) & 0,62 \\
\hline & & & Prob. Chi-Square(12) & 0,55 \\
\hline & & & Prob. ADF & 0,00 \\
\hline & & & KPSS (valor crítico a & \\
\hline & & & $5 \%$ de 0,46$)$ & 0,26 \\
\hline & & & $\begin{array}{l}\text { MSB (varor crítico a } 5 \% \\
\text { de } 0,23 \text { ) }\end{array}$ & 3,09 \\
\hline
\end{tabular}




\section{Comentários sobre os resultados segundo tipologia pós-keynesiana}

\section{a) Inflação de demanda?}

Na classificação pós-keynesiana, a inflação de demanda acontece quando existe um excesso de demanda frente à capacidade produtiva, aos estoques acumulados e/ou à disponibilidade de mão de obra. Nas equações estimadas neste trabalho, tanto em nível agregado como em nível desagregado por categoria de uso, não foi encontrado suporte econométrico para a existência de inflação de demanda na década de 2000 (ver Quadros 1, 3 e 5 a 8). Nenhum dos indicadores de excesso de demanda se mostrou estatisticamente significativo na equação de inflação ao consumidor. Mesmo no caso dos serviços cujos preços não são administrados na esfera pública, não foi encontrada significância estatística para os indicadores de demanda (ver Quadro 7).

\section{b) Inflação importada e inflação de commodities}

As estimativas apontam que a inflação importada foi o principal tipo verificado de inflação na economia brasileira na década de 2000 , seja por causa das pressões cambiais (ocorridas, grosso modo, na primeira metade da década) seja por causa das pressões dos preços das commodities (relevante principalmente na segunda metade da década).

A variação cambial e a inflação de commodities apresentaram forte significância estatística, tanto na inflação cheia como nas componentes desagregadas de preços ao consumidor (ver Quadros 1, 3, 5, 6 e 8), apresentando falta de significância estatística apenas na equação dos serviços não monitorados pelo governo (Quadro 7). Nota-se, contudo, que a variação das commodities tem coeficiente levemente inferior ao coeficiente da variação cambial ${ }^{9}$. Isso pode ser reflexo do fato de a inflação importada não ser inteiramente denominada por commodities, mas também pelo preço de bens manufaturados. Alternativamente, o resultado pode ser interpretado como indício de que o canal da transmissão da variação cambial aos preços não é restrito ao canal direto da inflação importada.

Nos anos 2000 ocorreu uma correlação média negativa entre a taxa de câmbio, de um lado, e os preços das commodities de outro. Para a inflação brasileira, tal relação inversa foi providencial, pois o comportamento de um atuou no sentido de amenizar as pressões do outro. O único período em que os dois fatores atuaram conjuntamente em direção altista foi no final de 2002/início de

(9) Cerca de $60 \%(0,018 /(0,018+0,012))$ da inflação importada são referentes às variações cambiais e $40 \%$, à variação dos preços das commodities. 
2003, o que explica o alto patamar da inflação alcançado ao longo do ano de 2003 (ver Bastos; Braga, 2010) ${ }^{10}$.

No setor de serviços (não monitorados), como era de se esperar, não houve influência da inflação importada: nem a variação cambial nem a inflação de commodities em dólares apresentaram significância estatística na equação dos preços desses serviços (Quadro 7).

\section{c) Inflação de lucro (inflação de grau de monopólio ou de preços monitorados) ${ }^{11}$}

Os preços administrados exerceram forte pressão sobre a inflação ao consumidor até 2005, especialmente em virtude dos preços dos combustíveis (mais especificamente, gasolina), da energia elétrica e da telefonia ${ }^{12}$.

Pelas regras impostas durante o processo de privatização, nas quais tentavam preservar o valor das receitas em dólar dos novos proprietários, alguns desses itens acabaram por atrelar esses preços de uma forma indireta aos movimentos da taxa de câmbio. Tais regras permitiram que esses preços tivessem reajustes muito acima da média da inflação durante o período de desvalorização cambial. Esse aumento pode ser caracterizado por uma "inflação de grau de monopólio" e se refere ao lucro acima daquele obtido sob condições de concorrência.

Especificamente no caso da energia elétrica, a influência da variação cambial é sentida de forma direta, uma vez que a energia gerada por Itaipu é denominada em dólares. Em 2004, ocorreu uma mudança do marco regulatório,

(10) O comportamento muito volátil dos preços dos alimentos e o peso elevado sobre o índice agregado fizeram com que o índice dos bens de consumo não duráveis fosse um dos que mais pressionaram a inflação em alguns anos (como ocorreu em 2007 e 2008) e que mais aliviaram a inflação em outros (como aconteceu em 2005 e 2006). A inflação dos bens de consumo semiduráveis parece ter sido beneficiada pela variação cambial. Desde 2005 apresentam crescimento moderado, próximo à meta estipulada pelo Banco Central do Brasil (BCB), ainda que sem a mesma tendência deflacionista dos preços dos bens duráveis.

(11) A única inflação de lucros considerada nessa seção é a chamada inflação de preços administrados por Lavoie (1992). Isso porque é o único caso em que existe algum tipo de informação sobre margens de lucro, uma vez que são acompanhadas pelo governo. Uma evidência de inflação de lucro determinada pela taxa de juros, que leva a um conflito indireto entre rentistas e trabalhadores é encontrada em Bastos e Braga (2010).

(12) Os preços administrados incluem os impostos e as taxas - Imposto sobre a Propriedade de Veículos Automotores (IPVA), Imposto Predial e Territorial Urbano (IPTU) e taxas de água e esgoto - e as tarifas dos serviços de utilidade pública (telefonia, energia elétrica, planos de saúde e pedágios). Além disso, incluem também itens sujeitos a acompanhamento por parte de órgãos do Estado, como medicamentos, passagens aéreas e derivados de petróleo. Representam cerca de $30 \%$ do IPCA. A lista completa dos itens no IPCA é a seguinte: IPTU, taxa de água e esgoto, gás de bujão, gás encanado, energia elétrica residencial, ônibus urbano, ônibus intermunicipal, ônibus interestadual, ferry-boat, avião, metrô, navio, barco, táxi, trem, emplacamento e licença, pedágio, gasolina, álcool, óleo, óleo diesel, plano de saúde, cartório, jogos lotéricos, correios, telefone fixo, telefone público e telefone celular. 
racionalizando a compra da energia pelas distribuidoras pelo preço mais baixo disponível no mercado, através de leilões, evitando que distribuidoras comprassem ao preço mais alto, cobrado por usinas termelétricas participantes de seus conglomerados. Além disso, para os leilões de energia nova, o indexador de reajuste passou a ser o IPCA ${ }^{13}$. Atualmente, somente uma parcela da componente da fórmula de reajuste (encargos tarifários) é ainda referenciada ao IGP-M.

No caso dos contratos dos serviços telefônicos, houve uma alteração na regulação em janeiro de 2006 (devido ao vencimento dos contratos realizados na época das privatizações). A primeira mudança foi a substituição do Índice Geral de Preços-Disponibilidade Interna (IGP-DI) pelo Índice de Serviços de Telecomunicação (IST), composto por uma combinação de outros índices, dentre eles o IPCA, o Índice Nacional de Preços ao Consumidor (INPC), o IGP-DI e o IGP-M. A mudança do índice atuou no sentido de amortecer as fortes oscilações do IGP-DI e foi benéfica especialmente no ano 2008 quando o IGP-DI aumentou 11,2\%, o IPCA, 5,9\%, e o IST, 6,6\%. Além disso, a Agência Nacional de Telecomunicações (Anatel) alterou a regulação, no momento da reformulação contratual, modificando a fórmula do chamado fator X. Este fator do mecanismo de "preço-teto" (price-cap) consiste em um desconto após o reajuste por determinado índice de preço. Anteriormente, este fator era praticamente estático; com as novas regras, passou a ter uma fórmula que o vincula ao crescimento da produtividade. $\mathrm{O}$ resultado da nova regulamentação foi um aumento desse desconto, uma redução dos tetos tarifários e um compartilhamento com os consumidores dos ganhos de produtividade do setor (ver Mattos, 2007).

As alterações contratuais foram refletidas nos preços: o item energia elétrica passou a ter crescimento médio abaixo da meta de inflação. $O$ grupo 'comunicações' do IPCA mostrou uma clara mudança de comportamento no mês de reajuste (todo julho) a partir de 2006; a partir deste ano, no acumulado em 12 meses, sua variação ocorreu a uma média de $1,5 \%$ ao ano (a.a.).

No caso dos combustíveis, a regra de reajuste da Petrobras é de não repassar oscilações de curto prazo aos preços dos combustíveis. Além disso, desde 2006 o Ministério da Fazenda (MF) adotou a política da Contribuição de Intervenção no Domínio Econômico (Cide-flexível), reduzindo temporariamente a tributação sobre a gasolina e o óleo diesel durante picos de preço do petróleo no mercado internacional. $\mathrm{O}$ efeito destas duas políticas foi determinante para o comportamento da inflação na segunda metade da década, quando a variação (já convertida em reais) de cerca de 40\% do preço do petróleo ocorrida em 2007-2008 não foi inteiramente repassada ao preço dos combustíveis. Os preços da gasolina e do diesel nas refinarias permaneceram inalterados desde o final de 2005 até maio

(13) Tais mudanças se fizeram sentir a parir de 2006, uma vez que em 2005 aconteceram reajustes em decorrência do repasse de componentes financeiros, o chamado passivo regulatório (ver Souza, 2007). 
de 2008. Em maio de 2008 houve reajuste de $10 \%$, no caso da gasolina e $15 \%$ no caso do diesel. O impacto sobre o consumidor do reajuste da gasolina, no entanto, foi nulo (a componente gasolina do IPCA variou em 0,0\% no acumulado em 12 meses) uma vez que foi compensado pela diminuição da Cide. Em 2009 e 2010 a variação percentual no IPCA continuou baixa no caso da gasolina (cerca de $1,5 \%$ a.a.) ${ }^{14}$ enquanto o óleo diesel passou a registrar deflação.

A dinâmica da série da inflação de preços monitorados (acumulada em 12 meses) sugere uma mudança estrutural na tendência da série, o que corresponde a uma forte diminuição da variância da inflação mensal. Essa mudança na variância da inflação mensal resultou no efeito ARCH encontrado no modelo ARMAX dos preços monitorados (Quadro 2). Esse efeito de variância condicionada não constante foi modelado a partir de um GARCH-M, com a inclusão da variância condicionada na equação principal (esperança condicionada) do GARCH (Quadro $3)^{15}$. O gráfico da variância condicionada estimada por este modelo mostra uma clara estabilidade da mesma a partir de 2006, sugerindo a eficácia de políticas não monetárias de combate à inflação (Gráfico 1).

Gráfico 1

Variância condicionada do GARCH-M $(1,1)$

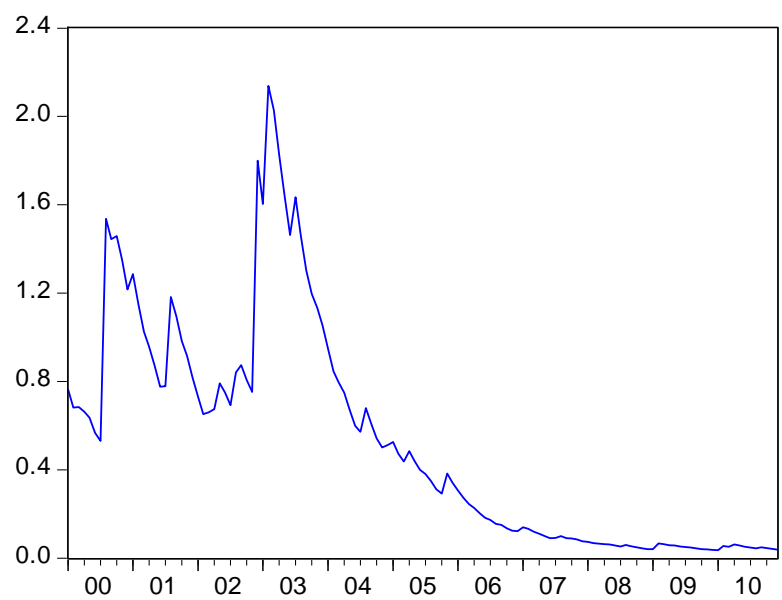

Um ponto importante a ser ressaltado é que a esperança condicionada do modelo levou em consideração a variação cambial e a inflação de commodities, que se mostraram bastante significativas estatisticamente como variáveis explicativas. Assim a valorização cambial da segunda metade da década certamente contribuiu para estabilizar os preços monitorados. Porém, ainda assim, o modelo apresentou

(14) Média do índice acumulado em 12 meses ocorrida em todos os meses entre janeiro de 2009 até agosto de 2010 .

(15) Essas mudanças nas regras dos preços também foram interpretadas por Martinez e Cerqueira (2010) como uma alteração em uma componente "estrutural" desses preços. 
efeito ARCH e a variância condicionada foi significativa na equação da esperança condicionada. Essa é uma evidência de que a estabilidade alcançada a partir de 2006 não foi causada somente pela valorização cambial, mas também pelas medidas adotadas pelo governo de alteração nas regras do jogo e do forte crescimento da produtividade nos setores em que houve essa mudança.

\section{d) Inflação salarial}

O sistema de equações para a inflação de preço e salarial indica que a variação salarial é uma variável significativa na explicação dos preços, mais especificamente dos preços dos serviços (ver Quadros 1, 6 e 8). A variação dos salários médios por sua vez foi significativa estatisticamente sobre a inflação de serviços e de bens de consumo não duráveis. Esta última categoria inclui o item Alimentação fora do domicílio que pode ser encarada como sendo, parcialmente, uma prestação de serviços (Quadros 6 e 8).

De 2000 até 2004, os salários nominais médios cresceram abaixo da inflação (medida pelo IPCA), com média de 3,2\% a.a. A partir de 2005, a variação dos salários nominais ficou acima da inflação geral, passando a crescer numa média de 8,0\% a.a. Os salários nominais apresentaram movimento pró-cíclico, variando com maior intensidade no período de crescimento mais acelerado do Produto Interno Bruto (PIB). Para cada diminuição de um ponto percentual (p.p.) da taxa de desemprego, considerados constantes todos os outros fatores que afetam os salários, há um aumento de 0,23 p.p. dos salários nominais (Quadro 1). Tal verificação empírica é interpretada aqui como na literatura clássica, na qual períodos de demanda aquecida permitem um ambiente em que os trabalhadores possam barganhar melhores expansões salariais.

No período de crescimento salarial acima da inflação, o SM apresentou ganho ainda superior ao do salário médio. O efeito do SM sobre a inflação é extremamente difícil de captar, devido ao fato de os reajustes serem concentrados em apenas um mês do ano, causando descontinuidades abruptas nas variações percentuais da série. Além disso, os meses desses reajustes variaram ao longo dos anos: de 2000 a 2003 os reajustes foram em abril, em 2004 e 2005, maio; em 2006 e 2007, abril; em, 2008, março; em 2009, fevereiro e em 2010, janeiro. De fato, não foi possível encontrar evidência estatística no modelo para tal variável nas equações estimadas.

Contudo, algumas evidências sugerem que o SM foi importante para explicar a evolução de preços em alguns setores. Em primeiro lugar, o número de trabalhadores com salário equivalente ao mínimo ${ }^{16}$ foi cerca de $16 \%$ do número total de empregados em 2009 (refletindo um aumento em relação à participação de $10 \%$ em 1999). Em segundo lugar, o crescimento dos rendimentos dos

(16) Ao valor do SM foi adicionado, para mais ou para menos, 3,6\% do mesmo, para considerar arredondamentos na declaração da Pesquisa Nacional por Amostra de Domicílios (PNAD)/IBGE. 
trabalhadores no setor informal (sem carteira assinada) e por conta própria foi superior ao do setor formal. Estes rendimentos podem ter sido influenciados pelo $\mathrm{SM}$, visto que este pode atuar como um importante sinalizador, um 'farol', servindo de base para reajustes destas remunerações. Os serviços com preços não administrados pela esfera pública cresceram acima da meta de inflação desde 2003, em uma média de aproximadamente 6,0\% a.a. A partir de 2006 ocorreu um aumento também do preço relativo dos serviços (serviços em relação a todas as outras componentes do IPCA).

Dessa forma foi realizado um tratamento estatístico de suavização da variação salarial acumulada do SM em 12 meses e comparada à inflação de serviços. O Gráfico 2, para o período de 1999 a 2010, e seu detalhe de 2003 a 2010 (Gráfico 3), mostram que as duas séries "caminharam juntas" ao longo desta década de 2000.

Gráfico 2

Inflação nos serviços e salário mínimo

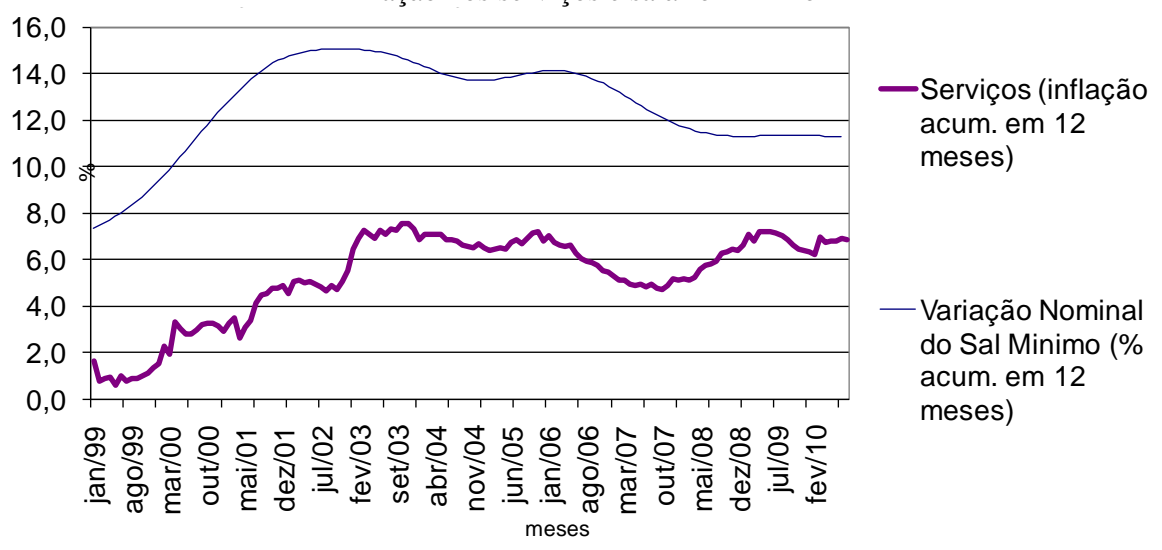

Fontes: IBGE e MTE (Série do salário mínimo suavizada pelo filtro HP).

Gráfico 3

Inflação nos serviços e salário mínimo (detalhe)

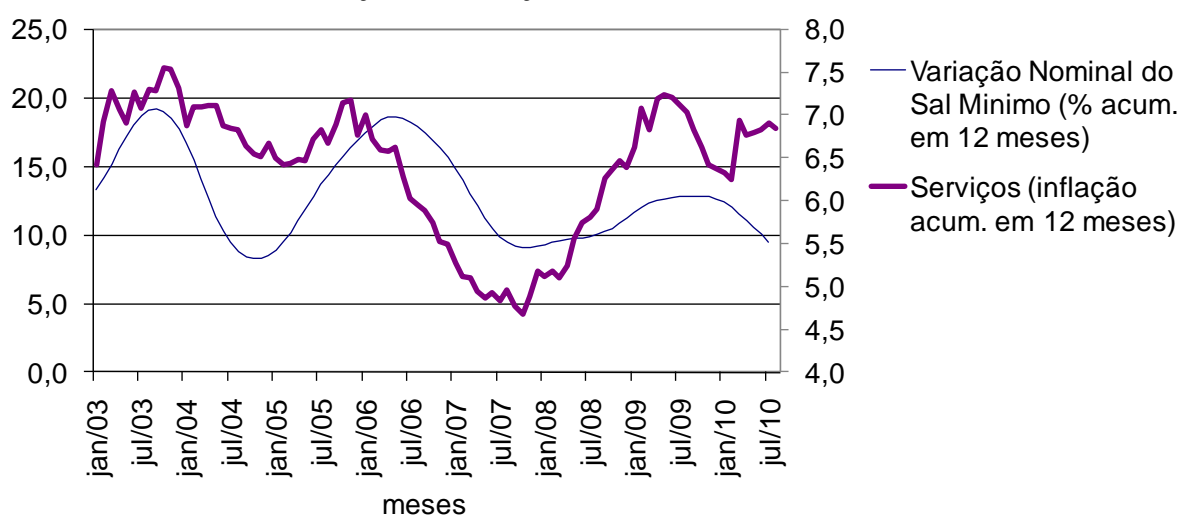

Fontes: IBGE e MTE (Série do salário mínimo suavizada pelo filtro HP no eixo esquerdo. 


\section{e) $\mathbf{O}$ crescimento da produtividade}

Como exposto no referencial metodológico, uma variável importante para acomodar o conflito distributivo latente é a mudança na tecnologia e o consequente crescimento da produtividade. Ao longo da década de 2000 houve aumento da produtividade total da economia (crescimento de $1,7 \%$ da produtividade total dos fatores de 2003 a 2007) e uma redução da defasagem tecnológica em relação aos países desenvolvidos (ver Barbosa Filho; Pessoa; Veloso, 2010; Amitrano, 2010). Esse crescimento da produtividade foi naturalmente maior no setor industrial, sujeito a se beneficiar de ganhos de escala e da tecnologia incorporada nas máquinas e equipamentos importados ${ }^{17}$, e parece ter influenciado os preços dos bens de consumo duráveis. Desde o final de 2005, o preço de bens de consumo duráveis cresceu a um nível muito abaixo da inflação agregada ao consumidor (apresentando variação praticamente nula). Esse parece ser o efeito conjunto da valorização cambial, da exposição à concorrência externa, de economias de escala (e, portanto, redução do custo unitário de produção), além da política temporária de redução dos tributos devido à crise econômica de $2008^{18}$.

$\mathrm{Na}$ indústria, esse crescimento da produtividade foi responsável por manter o custo unitário do trabalho real (isto é, o salário real médio vis-à-vis a produtividade) em patamar aproximadamente invariante ao longo da década. $\mathrm{O}$ índice com base 100 em janeiro de 2001 atingiu o nível de 94,5 em dezembro de 2010 no caso da indústria geral (e 94,0 na indústria de transformação). Mais especificamente, o índice apresentou leve queda nos primeiros anos da década, cresceu durante a crise de 2008 e voltou a declinar parcialmente no final da década.

Dessa forma, os ganhos agregados de produtividade compensaram (ainda que parcialmente) o crescimento dos salários médios. O baixo crescimento do preço dos bens duráveis (e dos preços monitorados pelo governo como vimos na seção 2), por sua vez, compensou parcialmente o crescimento do preço dos serviços.

(17) O exame das diferenças de ritmo de crescimento da produtividade entre os setores industrial, agropecuária e serviços foge ao escopo deste trabalho. Contudo, uma medida aproximada indica que, de 2003 a 2008, o crescimento da produtividade na indústria foi de 18,0\% e nesses tipos de serviços, 12,9\% - levando em consideração dados das Contas Nacionais, da PME e da Pesquisa Industrial Mensal de Emprego e Salário (Pimes) do IBGE. Essas medidas serão tema para a próxima pesquisa. A comparação internacional da evolução do preço relativo dos serviços indica uma tendência de aumento em diversos países ao longo das últimas décadas. Esse também será tema para trabalhos futuros de pesquisa.

(18) Nessa categoria, os itens que têm maior peso são os automóveis. O nível do preço de automóveis novos e usados declinou (mesmo em termos absolutos) a partir do final de 2005. Em 2008 essa queda foi acentuada pela política de redução do IPI. Mesmo com a volta do imposto ao patamar pré-crise, os preços dos automóveis mantiveram-se em patamares reduzidos. Tal dinâmica é influência direta da taxa cambial, assim como do aumento da concorrência no setor. Porém as margens de lucro das montadoras podem ter ficado preservadas diante das economias de escala e redução dos custos, resultantes do aumento da produção. 
Porém, apesar de, na média, os salários serem compensados pelo crescimento médio da produtividade da economia, as diferenças setoriais podem significar pressões inflacionárias. O setor dos serviços não monitorados pelo governo é sujeito a menor crescimento da produtividade relativamente aos outros setores pela sua própria natureza. Ao mesmo tempo, é aquele em que incidiu maiores variações salariais, devido à política de reajuste do SM. Assim, o aumento do preço relativo desses serviços na década de 2000 foi reflexo: $i$ ) da desejada redistribuição de renda decorrente da política de recuperação do poder de compra do SM e de um ambiente mais favorável ao crescimento dos salários médios, já que é um setor fortemente intensivo em trabalho; e ii) do menor crescimento da produtividade no setor de serviços vis-à-vis ao setor industrial.

\section{Implicações e limites dos instrumentos de política econômica anti- inflacionárias}

Historicamente, no Brasil, sempre foi difícil encontrar uma relação econométrica sistemática entre inflação e excesso de demanda. Esse fato empírico levou vários autores a considerar a política monetária pouco eficaz no sentido de reduzir a inflação, necessitando de uma taxa de juros excessivamente alta. Esses autores propõem políticas de rendas e de controle dos preços administrados como auxiliares no controle da inflação (como em Hermann, 2004; Sicsú, 2003).

Por outro lado, as estimativas da forte significância da taxa de câmbio como explicativa da inflação mostram que o canal do câmbio da política monetária pode ser extremamente eficaz para a estabilização dos preços. Vários autores, porém, apontam para os limites de tal política, devido aos efeitos indesejados de uma valorização cambial sobre o desempenho das exportações de manufaturados e a competitividade dos produtos nacionais no mercado interno (ver Bruno, 2009, para um exemplo).

Adicionalmente, os resultados das estimativas desse trabalho confirmam a falta de significância direta da demanda sobre a inflação, que se faz sentir apenas de forma indireta através do impacto sobre o poder de barganha dos trabalhadores. As estimativas para a década de 2000 apontam que os salários tiveram comportamento pró-cíclico, com a taxa de desemprego sendo significativa estatisticamente na expansão dos salários. A implicação é que medidas de contenção de demanda, tudo mais constante, podem ter o efeito perverso de frear a expansão dos salários. Por outro lado, não houve qualquer evidência de influência da demanda na equação dos preços, o que nos levou à interpretação de que o único canal de transmissão da demanda aos preços é pela via dos salários. Isto é, embora não se tenha trabalhado explicitamente com dados de margens de lucro, não há evidências de que o canal de transmissão da demanda aos preços se dê por ajustes nas margens de lucro, como supõem alguns autores pós-keynesianos (ver em 
Lavoie, 2002). De acordo com esta hipótese, políticas de contenção de demanda teriam o efeito de conter a inflação pelo limite ao aumento das margens de lucro. Além disso, segundo esta hipótese, as margens de lucro deveriam ser pró-cíclicas. Porém, existe grande discussão quanto às margens de lucro no Brasil, se são prócíclicas ou não. Feijó e Cerqueira (2008), por exemplo, encontram evidências de margens de lucro anticíclicas na indústria brasileira na década de 1990.

Finalmente, dependendo das prioridades do governo, o aumento dos preços relativos dos serviços não monitorados pelo governo pode ser encarado como um dado, e não combatido diretamente. Contudo, outras medidas compensatórias podem ser adotadas para evitar que tal processo de aumento do SM pressione a inflação, gerando a necessidade de aumentos da taxa de juros e de outras políticas de contenção de demanda agregada. Como vimos, a contenção da demanda pode levar a uma queda do crescimento do salário médio ameaçando então a própria escolha de uma política de redistribuição (nesse caso, funcional) da renda. Para uma dada inflação importada, a pressão dos preços dos serviços não monitorados pelo governo pode gerar um conflito inter-salarial (wage-wage) caso exista uma reação dos salários industriais ou do setor agropecuário acima do crescimento da produtividade em seus setores. Porém, quando existe uma reação de política econômica contracionista, os salários não vinculados à política de SM são acomodados, perdendo a disputa por maior participação na renda, para dada inflação importada. Dessa forma, passamos a discutir na próxima seção algumas dessas medidas adicionais que podem ser auxiliares no controle da inflação.

\section{Políticas anti-inflacionárias não monetárias para o desenvolvimento}

Duas conclusões podem ser tiradas do diagnóstico anteriormente descrito: em primeiro lugar a importância dos ganhos de produtividade para diminuir o conflito distributivo; em segundo lugar, a importância de boas práticas de regulação dos preços administrados e de atuação da política tributária.

O uso de política tributária no sentido de torná-la mais progressiva é ressaltado na literatura da inflação de custo da Comissão Econômica para a América Latina e o Caribe (Cepal) (Vásquez, 1957). A flexibilização da cobrança da Cide combustível é uma demonstração de que a política tributária é eficaz como política auxiliar no combate à inflação. A análise da trajetória dos preços dos automóveis sugere que a redução do IPI foi de fato repassada aos preços, estimulando as vendas durante a crise internacional. Em termos mais gerais, uma reforma tributária voltada para a diminuição da carga dos impostos sobre produtos, tipicamente regressivos, e um peso relativo maior dos impostos diretos (sobre a renda e o patrimônio) podem contribuir para a estabilidade dos preços. É importante ressaltar que tal alteração tributária não pode prejudicar o necessário financiamento dos investimentos públicos. O papel da Cide flexível e o impacto do 
IPI podem servir de inspiração para mudanças na legislação dos tributos que incidem sobre os alimentos de forma a auxiliar no combate à inflação de alimentos, através do amortecimento das oscilações dos preços das commodities agrícolas quando repassadas aos preços aos consumidores. $\mathrm{O}$ aumento de impostos sobre as exportações de algumas commodities ou a retirada de subsídios à exportação como forma de direcionamento para o mercado interno são opções a serem estudadas pelo governo.

No caso dos preços públicos, as mudanças do marco regulatório no setor de comunicação e energia elétrica são importantes evidências de como as regras podem contribuir para a obtenção de preços que impeçam um abuso do poder de mercado por parte das concessionárias dos serviços. Novos contratos ou futuras revisões contratuais devem dar preferência a regras de indexação baseadas nas variações de índices setoriais próprios, que reflitam corretamente a composição dos custos; que estimulem o controle de custos por parte das empresas, a transparência na divulgação dos balanços contábeis, os ganhos de produtividade (sem prejudicar a qualidade dos serviços) e a ampliação dos investimentos.

Outras medidas que tenham impacto sobre os preços, inspiradas em políticas de segurança alimentar e energética ou políticas antitrustes, ou de naturezas diversas também podem ser estudadas pelo governo. A experiência recente mostra que a combinação de autossuficiência em petróleo e a propriedade majoritariamente estatal da Petrobras adicionam um grau de liberdade à política anti-inflacionária brasileira, ainda mais se lembrarmos de que a política de metas de inflação brasileira tem como indicador a inflação cheia e não apenas o núcleo (core) - índice de preços expurgado dos efeitos de preços voláteis como combustíveis e alimentos. É obvio que tal política não deve comprometer a própria estratégia da empresa. Porém, sempre que houver oscilação expressiva do preço do petróleo acima da variação de custos de produção, haverá um espaço significativo de atuação da Petrobras na estabilização dos preços no Brasil.

Cabe ainda ressaltar que a redução da variação no índice de energia elétrica do IPCA coincidente com o início da alteração no marco regulatório no setor de energia elétrica, e a desarticulação dos conglomerados que favoreciam suas próprias termelétricas, foram evidências de que a estratégia de investimento em hidrelétricas (mesmo a fio d'água) é claramente superior às termelétricas, pois evita o custo marginal mais elevado no setor. A opção por tecnologias adequadas nas estratégias de desenvolvimento devem levar em consideração o impacto que surtirá sobre a formação dos preços.

Os ganhos de produtividade também dependem de estratégias microeconômicas adequadas, tais como: políticas industriais específicas, políticas 
de incentivo à inovação tecnológica, políticas de garantia de acesso ao crédito pelas empresas e o investimento em infraestrutura.

A atuação direta de aportes de investimentos públicos é fundamental para o setor de infraestrutura. No setor de transporte urbano, são essenciais o investimento público federal e/ou a abertura de linhas especiais de crédito para estados, municípios e o próprio setor privado, especialmente para a construção de rodoanéis e metrôs, visando ao fim dos engarrafamentos. O melhor fluxo de veículos permitiria um melhor ambiente para ganhos de produtividade do setor de serviços. No caso do transporte de carga, o custo médio vigente no Brasil ainda é considerado muito alto para padrões internacionais. A melhoria da malha rodoviária e ferroviária e a ampliação dos portos são imprescindíveis para a geração de importantes ganhos de produtividade e consequentes reduções nos custos de transporte e distribuição dos produtos agrícolas e industriais. Assim como no transporte nas cidades, somente um grande aumento dos investimentos poderá trazer ganhos de produtividade para este segmento.

Outras iniciativas também são importantes para incentivar o adensamento da cadeia produtiva. É o caso, por exemplo, do aumento dos investimentos em atividade de agroquímicos e fertilizantes para reduzir os custos e aumentar a produtividade no campo, podendo se tornar um importante aliado para o combate à inflação de alimentos. A diminuição da dependência de importação desse insumo básico é uma política de segurança alimentar e pode diminuir a elasticidade de resposta da variação dos preços internos aos preços internacionais e à variação cambial. É claro que os preços internacionais sempre serão balizadores para os preços internos, pois podem representar alternativas de rentabilidades superiores, já que grande parte da produção agrícola tem a possibilidade de ser direcionada ao mercado externo. Contudo, o Brasil se tornou desde 2007 o mais importante player do setor, devido ao rápido crescimento da produção e da produtividade, superior ao de outros países. Portanto, os grandes produtores brasileiros atuantes no setor não são simples tomadores de preços. Enquanto não houver o barateamento dos custos do transporte e dos insumos, políticas agrícolas emergenciais como a de subsídios aos produtores, a criação de locais de armazenagem próximos a locais de consumo e estoques reguladores podem ser alternativas importantes, auxiliares no combate à inflação de alimentos.

É claro que algumas dessas medidas têm efeito imediato (como o caso da Cide ou estoques reguladores) e outras são de mais longo prazo. Porém, todas têm impacto benéfico e são igualmente importantes. Resta também a lição de medidas diversas que podem ser tentadas desde que tenham como base o correto diagnóstico de como a inflação brasileira é formada. 


\section{Conclusões}

Este trabalho apresenta estimativas econométricas para a inflação ao consumidor, segundo o IPCA. Foi adotado um modelo VAR-X, baseado em um modelo "estrutural" para estimativa da inflação que inclui a variação dos salários, além da inflação de bens e serviços, como variável endógena do modelo. Adicionalmente à modelagem do IPCA agregado, foram realizadas estimativas desagregadas do IPCA, a partir de modelos uniequacionais, separados entre preços monitorados e livres, estes últimos subdivididos em bens de consumo e serviços.

As estimativas apontam que a inflação ao consumidor agregada na década de 2000 foi marcada por duas influências principais: a variação cambial e a evolução dos preços das commodities. Estas são as variáveis mais importantes na explicação da inflação, permanecendo extremamente significativas mesmo diante de alterações na forma funcional ou no número de defasagens do modelo.

Outro fator importante para a explicação da inflação, que ganhou força a partir da segunda metade da década, foi o crescimento dos salários. O modelo indicou uma interação entre salários e preços dos bens finais estatisticamente significativa, mostrando grande resistência salarial por parte dos trabalhadores, fortalecidos após um período de contínua queda da taxa de desemprego. Esta influência aparece, sobretudo, na denominação dos preços livres que estão relacionados à prestação de serviços. Evidências ressaltadas por meio da análise exploratória dos dados permitem também inferir a importância do SM como variável explicativa na denominação destes preços.

O modelo "estrutural" utilizado na inflação agregada permitiu captar corretamente o efeito da demanda sobre a inflação brasileira. A demanda não determinou diretamente a dinâmica da inflação de bens e serviços. Sua influência ocorreu de forma indireta, através do impacto da taxa de desemprego sobre a evolução dos salários. Tal resultado implica a formação do conceito de que políticas de contenção de demanda têm a consequência perversa de frear a expansão dos salários. Como não houve evidência estatística de uma influência direta da demanda sobre a inflação de bens e serviços, o mesmo não pode ser dito para as margens de lucros. Dessa forma, a implicação que as estimativas realizadas neste trabalho sugerem é de que políticas de contenção de demanda, na atual conjuntura da economia brasileira, podem significar um desestímulo ao crescimento pró-cíclico apenas dos salários, contendo um viés antissalários na resolução do conflito distributivo entre salários e margens de lucro.

Por outro lado, dois vetores foram fundamentais para amenizar as pressões da taxa de câmbio da primeira metade da década, e dos preços das commodities e dos salários, na segunda metade da década. $\mathrm{O}$ primeiro foi o crescimento da produtividade no período, que estabilizou o custo unitário do trabalho, 
principalmente na indústria. $\mathrm{O}$ segundo vetor refere-se a mudanças ocorridas nos preços de alguns bens e serviços monitorados. Essas mudanças ocorreram devido a uma série de medidas de natureza regulatória e de política tributária adotadas pelo governo a partir de 2006.

As estimativas realizadas, a partir da modelagem GARCH-M, para os preços monitorados possibilitam mostrar que políticas não monetárias, de natureza regulatória, tributária ou que resultem no crescimento da produtividade são eficazes no combate à inflação. $O$ trabalho sugere a continuação da adoção de tais políticas públicas que tenham como resultado o crescimento da produtividade e o controle de aumentos excessivos nos preços administrados.

\section{Referências bibliográficas}

AMITRANO, C. R. C. O regime de crescimento econômico brasileiro: uma apreciação sobre o período 1995-2009”. In: IPEA (Org.). Brasil em desenvolvimento. Brasília, 2010. No prelo.

BARBOSA FILHO, F. H.; PESSOA, S. A.; VELOSO, F. A. Evolução da produtividade total dos fatores na economia brasileira com ênfase no capital humano - 1992-2007. Revista Brasileira de Economia, Rio de Janeiro, v. 64, n. 2, abr./jun. 2010.

BASTOS, C.; BRAGA, J. M. Conflito distributivo e inflação no Brasil: uma aplicação ao período recente. In: ENCONTRO NACIONAL DA SOCIEDADE DE ECONOMIA POLÍTICA, 15. São Luis do Maranhão, jun. 2010.

BRUNO, M. Regime cambial e mudança estrutural na indústria de transformação brasileira: novas evidências para o período (1994-2008). In: ENCONTRO NACIONAL DA ANPEC, 37. Foz do Iguaçu, 2009.

DRUMMOND, E.; PORCILE, G. Um modelo dinâmico de macroeconomia aberta com metas de inflação, 'conflict claims' e equilíbrio na conta corrente. In: ENCONTRO DA ASSOCIAÇÃO KEYNESIANA BRASILEIRA, 3. 2010.

ELlER, J. E.; GORDON, R. Nesting the new Keynesian Phillips Curve within the mainstream model of U.S. inflation dynamics draft of a paper to be presented at CEPR conference: the Phillips Curve Revisited. Berlin Hilton, Berlin, Germany, June 5-6, 2003.

FAIR, R. Testing price equations. European Economic Review, v. 52, issue 8, p. 1.4241.437, Nov. 2008.

FEIJÓ, C.; CERQUEIRA, L. F. Comportamento do mark up na indústria brasileira nos anos 1990: evidências empíricas. Universidade Federal Fluminense, jun. 2008 (Texto para Discussão, n. 237).

FLASCHEL, P.; KAUERMANN, G. E.; SEMMLER, W. Testing wage and price Phillips Curves for The United States. Metroeconomica, v. 55, issue 4, 2007. 
FUHRER, J. The (un)importance of forward-looking behavior in price specifications. Journal of Money Credit, and Banking, v, 29, n. 3, 1997.

HERMANN, J. O trade-off do crescimento do Brasil nos anos 1990-2000: a análise crítica e alternativas de política monetária. Econômica, Rio de Janeiro, v. 6 , n. 2, p. 261-289, dez. 2004.

LAVOIE , M. Foundations of post-Keynesian economic analysis. Cheltenhan: Edward Elgar, 1992.

MARTINEZ, T.; CERQUEIRA, V. Estrutura da inflação brasileira. Seminários, Rio de Janeiro, Ipea, n. 363, 2010.

MATTOS, C. Um panorama das tarifas de telecomunicações no Brasil pós-privatização. Políticas de preços públicos no Brasil, Câmara dos Deputados, 2007.

POLLIN, R. Wage bargaining and the US Phillips Curve: was greenspan right about traumatized workers in the 90s? Political Economy Research Institute, University of Massachusetts Amherst, 2002. Mimeografado.

ROWTHORN, B. Conflict, inflation and money. Cambridge Journal of Economics, v. 1, n. 3, p. 215-239, 1977.

SAAD FILHO, A. Inflation: radical interpretations, In: ENCONTRO NACIONAL DE ECONOMIA POLÍTICA, 4. Porto Alegre, 1999.

SETTERFIELD, M. Worker insecurity and U.S. macroeconomic performance during the 1990s. Trinity College, Department of Economics, 2004.

SICSÚ, J. Políticas não-monetárias de controle da inflação: uma proposta pós-keynesiana. Análise Econômica, Ciências Econômicas - Universidade Federal do Rio Grande do Sul (UFRGS), 2003.

SOUZA, F. Regras de preço no setor de energia em políticas de preços públicos no Brasil. Câmara dos Deputados, 2007.

STAIGER, D.; STOCK, J. E.; WATSON, M. How precise are estimates of the natural rate of unemployment. Mar. 1996 (NBER Working Papers, n. 5.477).

Prices, wages and the U. S. NAIRU in the 1990s. In: KRUEGER, A. B.; SOLOW, R. M. (Ed). The roaring nineties: can full employment be sustained? Russell Sage Foundation, 2001.

STIRATI, A. Inflation, unemployment and hysteresis: an alternative view. Review of Political Economy, 2001.

VÁSQUEZ, J. Inflação e desenvolvimento econômico no Chile. In: CEPAL; BIELSCHOWSKY, R. (Org.). Cinquenta anos de pensamento. Editora Record, v. 2, 1957. 


\section{Anexo}

A série para medir os salários nominais é o rendimento nominal médio habitualmente recebido pela população ocupada (PO) da PME do IBGE. Tal variável tem a limitação de se restringir às principais Regiões Metropolitanas (RMs) do país: Rio de Janeiro, São Paulo, Salvador, Belo Horizonte, Recife e Porto Alegre. Devido à mudança metodológica realizada pela pesquisa em 2003, quando foram consideradas estimativas para o período de 1999 a 2008, a série foi encadeada com a série do rendimento nominal médio recebido pela PO da PME Antiga Metodologia. Para as estimativas foi realizado um tratamento de ajuste da sazonalidade da série antiga visando compatibilizar as duas séries.

O grau de utilização da capacidade na indústria é o dado da Confederação Nacional da Indústria (CNI). A taxa de câmbio é a média da PTAX venda do BCB. $\mathrm{O}$ índice de preços de commodities utilizado é do Fundo Monetário Internacional (FMI) - International Financial Statistics-International Monetary Found (IFSIMF). A inflação ao consumidor é computada pelo IPCA do IBGE. O IGP-M é dado pela Fundação Getulio Vargas (FGV). O SM é divulgado pelo Ministério do Trabalho e Emprego (MTE).

As categorias de preços monitorados e livres, estes últimos subdivididos entre bens de consumo duráveis, não duráveis, semiduráveis e serviços, são dados do IPCA/IBGE reagrupados pelo $\mathrm{BCB}$. Os bens de consumo duráveis são constituídos principalmente pelo preço dos automóveis, eletrodomésticos, eletrônicos, mobiliário e material de obra. No caso de bens não duráveis o maior peso é de alimentos e bebidas e produtos de higiene pessoal. Os bens de consumo semiduráveis apresentam forte influência de vestuário, calçados, acessórios e brinquedos. A categoria denominada serviços compreende os chamados serviços pessoais (prestados por empregados domésticos, cabeleireiros, enfermeiros entre outros); serviços prestados por outros profissionais (tais como mestre de obras, mecânicos, bombeiros, entre outros) e serviços prestados pelos chamados profissionais liberais (médicos, dentistas, advogados, entre outros). Outras componentes com peso significativo são o aluguel residencial, as taxas condominiais e, especialmente, serviços da área de educação. O item cursos e cursos livres são, de longe, os que apresentam maior peso no índice, com forte influência, em particular, do ensino fundamental e do superior. 